\title{
Eight Ways to Erode Supervisor-Student Trust
}

\author{
Mbusiseni Celimpilo Dube
}

\author{
Social Sciences Education, \\ University of Zululand, \\ South Africa
}

\section{DOI: https://doi.org/10.36941/jesr-2021-0134}

\begin{abstract}
Trust between the supervisor and student is the most important element that can pave the way to the completion of a postgraduate degree. If the trust is eroded, it may be difficult for both supervisor and student to work in tandem for the common goal of completing a research study. Trust is the responsibility of both supervisor and student. Using an exploratory case study design, this study sought to explore issues that can erode supervisor-student trust. For data generation, semi-structured interviews were used for five master's and five PhD students who had completed their degrees; these students were purposively sampled. Data were thematically analysed, and revealed that a harsh manner of approach, a temperamental supervisor, long turnaround time, communication barriers, failure to understand a student's circumstances, impatience and intolerance, unfair treatment and disrespect can erode supervisor-student trust. Therefore, this study recommends that supervisors should always recognise that the manner in which they interact with students may either make or break that trust. Supervisors should give prompt feedback to students while students can still remember what they wrote. They should always bear in mind that students have other big responsibilities, and take that into account when relating with them.
\end{abstract}

Keywords: erode; supervisor; student; trust

\section{Introduction}

Are you aware that some supervisors' actions can erode the trust that students have in their supervisors? Supervisors should always watch their way of addressing their students as both persons and adults. If they are not careful enough, they may erode the trust students have in them, and possibly affect the success of the study. When students begin their research journey, they put all their trust in supervisors as people who can lead and support them throughout their research. When that trust is eroded, the working relations between a supervisor and student can also suffer. As supervisors mentor students, they should offer emotional support, which entails trust, concern and listening; appraisal support, which encapsulates affirmation and feedback; and instrumental support, which is about money, labour and time (House, 1981). According to House, these issues are related to trust. Supervisors should offer these types of support to their students, but ensure that they do not wear away their trust.

Bui (2014) argues that the successful completion of a research study depends on the quality of supervision and interaction between a supervisor and his/her student. Trust is one of the ways that 
can serve as a yardstick to measure quality supervision. If students trust their supervisor, they can adhere to all his/her instructions and guidance. Supervisors should always keep a check on their supervisory philosophy since it can influence students' expectations (Moxham, Dwyer, \& Reid-Searl, 2013). According to $\mathrm{Li}$ and Tan (2013), trust is possible if the parties involved engage in emotional investment and energy and reciprocation of care. Both supervisors and students should invest in trust for the study to succeed. Trust requires supervisors to impart positive attitudes and enthusiasm towards the guidance of students (Hauer ten Cate, Boscardin, Irby, Iobst \& Sullivan, 2014). Whatever supervisors do or say to students should have a positive bearing as well as create enthusiasm which can motivate them to undertake their work with ease and zeal, because for successful mentoring, a trusting relationship seems vital (Eller, Lev, \& Feurer, 2014). This study therefore seeks to explore issues that can erode supervisor-student trust, and thus help both supervisors and students to avoid them.

\section{Material Studied}

The following aspects emerged when studying material pertaining to supervision of post-graduate students. These aspects were perspectives on supervisor-student trust, students' expectations during supervision and student-supervisory ways of a caring supervisor and they are discussed fully below.

\subsection{Perspectives on supervisor-student trust}

Lundh, Palmgren and Stenfors (2019) argue that trust is a dynamic process based on students' performance. Their argument is that trust grows stronger or weaker depending on that performance, and supervisors look for signs of maturity and readiness from students. Lundh et al. identify professional conduct and good communication as important signs of readiness in students. The way students seek and respond to feedback can also shape the trust between them and supervisors. According to Lundh et al. (2019), trust is something mutual and interrelated. They contend that it becomes stronger or weaker as supervisors and students get to know each other. To this effect, issues of language and communication between the supervisor and student characterised by mutual openness, honesty, bravery and humour can help develop trust. A lack of dialogue can diminish trust, hence Lundh et al. (2019, p.15) argue that "by giving trust, you receive trust". Both supervisors and students should play safe so that they secure mutual trust.

Students trust the feedback they obtain from supervisors because they regard them as experts capable of pointing out mistakes and giving advice, and supervisors' comments help them to find the right direction (Zheng, Yu, Wang, \& Zhang, 2020), and be willing to implement their feedback. Nienaber, Romeike, Searle and Schewe (2015) regard supervisor attributes as antecedents of trust. The attributes they refer to are benevolence, which entails the degree to which the supervisor takes into account the students' needs and wellbeing; the supervisor's competence, which includes his/her knowledge and qualifications; and his/her integrity, which is about preserving organisational justice. In order to create, develop and sustain trust, both supervisor and student should clarify mutual expectations and their respective needs (Denis, Colet, \& Lison, 2019) from the beginning of the supervision process. Trust should be based on a vivid understanding of mutual expectations between supervisor and student, so these expectations should be clarified from the onset of their relationship. Trust in the supervisor neutralises the threats a student may fear about their relationship, and when students trust their supervisor, they feel safe to take interpersonal risks (Li \& Tan, 2013). In sum, their trust enables students to take risks that are worthwhile. Thus supervisors' actions can be positively related to trust (McKnight, Cummings, \& Chervany, 1998), hence supervisors should always keep a check on their actions against students so that they do not erode the trust between them. They should not only be mindful of their actions against students, but should also monitor their own honesty, moral behaviour and loyalty towards them, because these can enhance trust (Chen, Eberly, Chiang, Farh, \& Cheng, 2011). There are five components of emotional intelligence which can also 
shape supervisor-student trust; they are self-awareness, empathy, social expertise, personal influence and mastery of purpose and vision (Lynn, 2005). Both supervisor and student should be aware of these components so that they can work to create trust.

\subsection{Students' expectations during supervision}

The trust that students anticipate from supervisors is based on a number of expectations. These expectations are presented by Holloway and Walker (2000) and Thompson, Kirkman, Watson and Stewart (2005). They include support, encouragement, guidance and advice, constructive criticism. accessibility and availability at appropriate times. They also comprise reading and commenting on written work at acceptable times, ensuring that students have adequate facilities and resources, receive appropriate research training and advice on progress, and have enthusiastic, committed, knowledgeable and approachable supervision that helps them with academic and personal problems which may interfere with the smooth running of the research. As postgraduate students, they may trust their supervisors if they offer these services to them.

\subsection{Student-supervisory ways of a caring supervisor}

There are 10 ways of a caring supervisor, and these can shape trust between a supervisor and his/her student. A caring supervisor is sensitive to interaction, does not hold back on compliments and appreciation, motivates to write, clarifies the requirements of a research study, teaches time management, helps tolerate uncertainty and criticism, monitors the fulfilment of the quality criteria for the research project, provides any kind of feedback, and provides suggestions and options in addition to questions (Määttä, 2015). Supervisors should keep a check on the way they interact with students, and ensure that they do not hurt them. They should also be flexible in terms of emphasis during the supervision process. If students do well, supervisors should give compliments and show appreciation; this helps to motivate students and develop trust. Some students may be demotivated by a number of issues while under supervision, so supervisors should keep motivating them. Supervisors should always be explicit about their expectations of the study so that students know what is expected of them. Students may struggle with a number of things during their research; it is therefore the responsibility of the supervisor to clear away whatever confusion they may have. In order to build and sustain trust, supervisors should provide feedback timeously, and suggest new moves so as to assist students to complete their studies.

\section{Methodology}

The researcher employed a qualitative case study design that is powered by an interpretive paradigm. Yin (2012) point out that qualitative research offers a powerful opportunity to gain in-depth information and perspective through the eyes of the participants and their experiences as social actors. Consequently, the qualitative approach assisted the researcher to develop understanding of issues that can erode supervisor-student trust. The purpose of this study was to explore issues that can erode supervisor-student trust. Postgraduate students are closely involved with supervisors as they pursue their studies. They can erode or enhance the trust between them. Hence 1o students were purposively sampled and engaged. They were chosen on the basis that they had completed their master's degrees or PhDs, and therefore certainly knew about the importance of mutual trust with supervisors. Their engagement and experience with supervisors may have either eroded or enhanced their trust, so they were the most appropriate subjects for the study. Semi-structured interviews were employed to secure data from students. These were convenient because they enabled the interviewees to provide their own insights and reflections freely since they were in control of the interview sessions (Barbour, 2014). They also allowed the researcher to put follow-up questions if need be. Data were analysed thematically, thus allowing the researcher to identify and analyse 
patterns of meaning to illustrate themes that were important in the description of the phenomenon under study (Liñán \& Fayolle, 2015). Ethical issues were considered before the researcher undertook this study, and approval was granted to undertake it. All participants participated on their own volition as their rights to participate were spelled out in advance. Confidentiality and anonymity were addressed through pseudonyms. Participants were informed about the duration and safety of storing data, and when it would be destroyed.

\section{Findings}

The findings emanating from this study were reviewed as part of data analysis. Some categories of themes emerged in the process of data analysis. All these categories were written and assigned specific codes, and were carefully scanned later. After the classification of data guided by these categories, the interpretation, and presentation of findings were processed. The analysis of data using themes revealed nine issues that can erode supervisor-student trust. The first one was that the harsh manners of approach by supervisor can erode supervisor-student trust. Secondly, if a supervisor is temperamental the trust between a supervisor and student can be eroded. Thirdly, findings revealed that a long turnaround time from supervisor to student can erode trust. Fourthly, communication barriers between the supervisor and student can also erode trust. Fifthly, the supervisor's failure to understand a student's circumstances can erode trust. Sixthly, if the supervisor is impatient and intolerant of the student, trust can be eroded. Seventhly, if the supervisor treats students unfairly and disrespectfully, trust can be eroded. These issues are discussed fully in the following sections.

\section{Discussion of findings}

Themes that emerged from the findings are discussed below. In order to make reference to participants, $\mathrm{P}$ is used. For example, the first participant is referred to as $\mathrm{P} 1$.

\subsection{Harsh manner of approach}

Findings reveal that the harsh manner in which supervisors relate to their students can erode trust between them. Many a time, students rely on supervisors for guidance and support throughout their study. According to Hauer, ten Cate, Boscardin, Irby, Iobst and Sullivan (2014) supervisors should impart students with positive attitudes and enthusiasm when they offer guidance. Students expect good manners from supervisors during both verbal and non-verbal interactions. If supervisors do not interact appropriately with students, that can affect the trust the students should have in them. Supervisors should be careful of how they address and relate to their students.

For example, $\mathbf{P 2}$ commented "I spent time googling, searching, reading and writing. After submitting to my supervisor, he just returned my work with big words: 'Go and read again. This is bad.' I don't think he even read my stuff."

$\mathbf{P}_{2}$ also alluded to the action of her supervisor "I happened to be around where he works, and decided to go see him, but he chased me away, saying we never had an appointment. That was harsh. He should have squeezed me in since he knows I stay far from the university."

The assertion from $\mathrm{P}_{2}$ shows that he felt he was treated harshly after spending time researching and writing his piece. However, the supervisor did not even spend enough time reading and trying to make sense of what had been submitted, and this did not augur well for the student. The supervisor's action showed no sensitivity to supervisor-student interaction, which Määttä (2015) regards as an attribute of a caring supervisor. The action of the supervisor may be viewed as a lack of the attribute of sensitivity to supervisor-student interaction because the supervisor failed to spend time reading the work of the student. What the supervisor did was contrary to the suggestion of Thompson et al. (2005) who argue that students expect supervisors to read and comment on a written work at an acceptable time. The failure to do so became an issue that made the participant dubious about the 
supervisor. Also, Holloway and Walker (2000) suggest that students expect supervisors to be accessible and available at all times, and to understand their situations, and bear with them. In line with Holloway and Walker (200o) it seems like students are aware that they have pitfalls but supervisors should bear with them since as the word suggests, they are still students who are learning; so they are not perfect. To this extent, Chen, Eberly, Chiang, Farh and Cheng (2011) maintain that supervisors should mind their actions and moral behaviour towards students because they can erode or enhance trust.

Findings revealed expectations that some supervisors seem to be unaware of as they deal with their students and this manifested itself from the behaviour they showed their supervisees. It looks like some supervisors are unaware that students expect immediate feedback which can assist them keep their focus and motivate them to continue with their studies. Also, supervisors seem to be unaware that students expect them to be always available and accessible. Lastly, supervisors should always bear in mind that they need to develop enthusiasm which influence students to do their studies. These are all the issues that were only presented by the literature but seemingly supervisors never took them into cognisance when dealing with students' work. Therefore, the findings complemented the views from the literature.

\subsection{Long turnaround time}

When students submit their piece of work to supervisors, they expect quick feedback so as to know what they did right and what they need to improve. If supervisors take a long time to respond, trust can be eroded and the morale of the student can be affected. Students expect feedback promptly before they forget what they wrote and submitted. These concerns were presented by $\mathrm{P} 8, \mathrm{P}_{10}, \mathrm{P}_{5}$ and $\mathrm{P}_{3}$.

P8: "I submitted my work to my supervisor, and expected to receive my feedback in at least two weeks as per policy. It did not happen. I waited and waited, and decided to make a follow-up after four weeks, and my supervisor said he had not even started with it for some reason; I did not know whether to trust him again."

P1o: "After I submitted my work, my supervisor told me he could only look at it after four weeks since he was very busy. After four weeks there was still no feedback, and I didn't know whether to trust him anymore."

P5: "When I heard my friend saying she had received feedback from her supervisor within a week after submission, I even wished I was supervised by the same supervisor who was that quick in giving feedback."

P3: "A supervisor who gives you feedback within two weeks after submission encourages you to trust him as an expert in the field."

Students are frustrated by feedback that takes longer than expected. When they submit their papers they want to know where they need to improve so that they can work on that immediately. Zheng, Yu, Wang and Zhang (2020) suggest that comments from supervisor assist students to find the right direction. Therefore, students need direction or confirmation of direction immediately after submitting their work so that they know where and how to progress with their studies. If they do not receive feedback as they expect they may start losing trust because a long turnaround time affects not only their morale, but their work schedule. This is echoed by McKnight et al. (1998), who argue that supervisors' actions can be positively related to trust. So, immediate feedback from supervisors has a positive bearing on the supervisor-student trust. If supervisors do not act positively by giving feedback promptly, supervisor-student trust can be eroded. A failure to give feedback in good time can affect a supervisor's integrity, which is one of the attributes of a good supervisor (Nienaber et al., 2015). According to Zheng et al. (2020), supervisors are experts capable of pointing out mistakes and 
giving advice. It means that students expect to know their mistakes and receive advices promptly for they may lose focus if it takes long time.

Seemingly, findings suggest that some supervisors were not aware that giving their students immediate feedback is associated with integrity and is an attribute of a good supervisor; this can be attributed to the literature consulted. It is also unclear whether supervisors knew that their feedback always assist to give direction to their students. Had they be aware, they might have not delayed feedback as they did. So, the more there are delays on feedback, the more students may have to wait since they need direction and advice from their supervisors. Delaying feedback seem to have serious repercussions on students' progress hence McKnight et al. (1998) advices that supervisors' actions can be positively related to trust. So if supervisor' actions are not as expected by students, they may not contribute positively to students' progress.

\subsection{Communication barrier}

Communication is one of the mechanisms for healthy supervisor-student trust. If communication becomes a barrier, then trust can be eroded, hence the argument of Lundh, Palmgren and Stenfors (2019) that "by giving trust, you receive trust" seems substantive. Communication is one of the means for sustaining trust. It is incumbent on both supervisor and student to ensure that they maintain proper communication in order to nourish and sustain trust between them. Bui (2014) argues that a research study can be completed if there is quality interaction between supervisor and student. Interaction between a supervisor and student should be healthy so that everybody understands his/her role and this can be maintained through good communication.

P4: "Each time I submit my work she will not acknowledge receipt, will not give feedback in time, and when she sends it, I can't find her on her phone for clarity regarding comments she made; she won't answer, and never comes back to me. I will have to keep on trying her phone until I'm lucky. I keep praying for the grace of the Lord to complete my study and cut ties with her."

As per Lundh et al. (2019) the lack of dialogue can undermine trust. In other words, as noted above, a communication barrier has a bearing on supervisor-student trust. If communication is poor there may be no smooth sailing for the work that brings supervisor and student together. A student may be unclear about what to do since he/she always waits for the supervisor's guidance and support. Thompson et al. (2005) maintain that students expect support, encouragement, guidance and advice from their supervisors, and these expectations should be fulfilled immediately so as motivate and encourage students to work unremittingly.

The findings revealed that some supervisors seem to be unaware of the significance of communication in nourishing trust with their students. The manner some supervisors related to their students indicates that they do not understand the importance of communication in supervisorstudent trust as literature suggests. According to the literature, communication should be of a good quality but findings were mum regarding that. From what the literature affirms, it looks like some supervisors were unaware that as they do not communicate promptly with their students, that can undermine trust.

\subsection{Failure to understand students' circumstances}

Students are busy with a number of things while they pursue their studies. Most of them are working and thus studying part-time, and they are mothers and fathers of their families, with responsibilities on top of their studies. This calls for supervisors to always bear that in mind whenever dealing with them, as their students expect. However, if supervisors do not understand the circumstances that students find themselves in, trust can be eroded. 
P6: "I was supposed to submit my work the other day, but since my child was not well, I couldn't; as a married woman I had to take my child to hospital. The next day I received an email from my supervisor saying that I'm not serious about my work. I explained the challenge I had, but it was pointless."

P9: "I was not clear about the theoretical framework. I asked my supervisor to clarify it for me, but he told me to google search and read articles since I'm a postgraduate student. I told him I was not familiar with googling since I was a new student, but he insisted I should. I was hoping he would guide me on how to do that, but no, he didn't. He failed to understand that everything was new to me."

Li and Tan (2013) suggest that trust can be possible if the parties involved engage in emotional investment and energy, reciprocation of care, and increased subordinate satisfaction. It goes without saying that the supervisor in the reference above did not show signs of emotional investment and caring for students. Since Lundh et al. (2019) suggest that trust is mutual, it can be assumed that there is no mutual understanding between the supervisor and his students. It looks as if the supervisor lacks benevolence, which encompasses the degree to which the supervisor takes into account the students' needs and wellbeing (Nienaber et al., 2015). If a supervisor does not care, mutually understand his/her students and take their needs into account, trust can be eroded. Supervisors should always take the interests of their students to heart for their trust to persist.

The findings show that supervisors do not understand some issues that constitute trust with students. The literature indicates that both supervisors and students need to engage in emotional investment and energy. This suggests that both supervisors and students need to understand that for the study to be accomplished they also need to sympathise and empathise with each other. However, findings show that some supervisors did not sympathise with their students even when they presented valid reasons for their failure to do and submit work in time. Therefore, even though students did not explain how they want supervisors to treat them when they are experiencing problems but the literature was clear on what students expect from supervisors.

\subsection{Impatience and intolerance}

Since most postgraduate students have never been exposed to postgraduate study, they expect supervisors to be patient and tolerant with them. If they do not get this patience and tolerance, they may doubt their supervisors. If supervisors are not patient and tolerant, they may not assist their students to correct their mistakes and complete their studies.

P1: "After submitting my work he responded to say he expected that I would submit good work since we were workshopped about proposal writing. I told him this was the best I could do. Since he expected me to be knowing he criticised me for being lazy. I expected him to be patient with me and help me get through. Instead he accused me of being lazy."

One of the responsibilities of supervisors is to create the enthusiasm that can motivate students to undertake their work with ease and zeal (Eller, Lev, \& Feurer, 2014). Their patience and tolerance with students can create students' enthusiasm and motivation. On the other hand, impatience with students can demoralise them into losing their focus and interest. Therefore, it is imperative for supervisors to be patient and tolerant with their students. According to Määttä (2015) they should help them to tolerate uncertainty and criticism.

Findings suggest that students expect supervisors to tolerate them during the course of the study. They go to an extent of saying they feel offended if referred to as lazy. The actions of the supervisor went against creating enthusiasm expected from supervisor as explained by Eller, Lev and Feurer (2014). The supervisor failed to help the student tolerate uncertainty. It seems some supervisors are unaware of the consequences of their comments to students. Therefore, supervisors should be careful of how they react and comment to their students because they can demoralise and demotivate them. 


\subsection{Unfair treatment of students}

The way supervisors treat their students, through comment and interaction, can influence trust between them. The way students are treated can motivate or demotivate them. Consequently, supervisors should be wary about the way they treat their student so that they do not feel it is unfair.

P9: "I submitted my work and she returned feedback, and I worked on her comments and suggestions, and submitted again. She again returned work with new comments on the same sections I had worked on. I felt as if this lady didn't do her work well enough, and I found it unfair to go back and do something I thought I had put behind me."

P3: "When I was at my proposal stage, she suggested that I start by defining the concepts I was addressing, like approach and paradigm, and I did that. After marking my work, she changed without explanation and told me not to define concepts, but to get straight to the point since I was at the proposal stage. It was unfair to me to write and then delete due to a suggestion from the supervisor."

The literature reveals that supervisors should clarify requirements of a research (Määttä, 2015) for their students and it also asserts that students should receive appropriate research training (Thompson, Kirkman, Watson and Stewart, 2005). However, when supervisors change tunes when giving directions and clarifying what students need to do confuses students hence they find deem it as unfair treatment. This suggests that literature reveals some of the expectations from supervisors in order to avoid unfair treatment of students. Supervisors must be careful not to somersault because it can upset students. If they change their mind they should explain that to students so that they are not confused. If students think they are unfairly treated by their supervisors, they will lose trust in them.

\subsection{Disrespect}

Respect is the cornerstone of any relationship, whether at work or elsewhere. If disrespect can ruin any relationship, it can also ruin the trust between a supervisor and his/her student. This is a sensitive issue because with very rare exceptions, postgraduate students are adults, and many are married men and women. As they pursue their studies, they want to be respected by their supervisors. If they feel disrespected, they may start distrusting their supervisors and thus complicating the mammoth task ahead. Määttä (2015) argues that a caring supervisor is sensitive to interaction. This indicates that he/she should always be careful of how he/she relates with students because it can enhance or erode trust. For example,

$P_{5}$ asserted: “When I received feedback with words like 'rubbish', 'nonsense', 'why did you put this here?',

'I told you not to do this', I felt so disrespected and almost quit."

Findings reveal some words that seem unacceptable from supervisors' point of view. The literature, unfortunately, did not allude to such words. The use of such words is contrary to constructive criticism (Holloway and Walker, 2000) that students expect from their supervisors. The use of these words is totally unacceptable since they were referred to postgraduate students who are adults and they are grossly disrespectful. As Määttä (2015) argues, a caring supervisor can hardly use these words to his/her students. Therefore, supervisors should refrain from commenting in students' work with such words, they are disrespectful and can erode trust.

\subsection{A temperamental supervisor}

A temperamental supervisor is difficult to work with because a student cannot detect if the supervisor is in a good or bad mood. A student can come fully prepared to undertake a task with the 
guidance of the supervisor, but if it is a bad day for the supervisor, it can also be a bad day for the student, and that can affect the trust between them. Thompson et al. (2005) contend that personal problems should not interfere with work. A moody supervisor can derail the morale of the student.

P1o: "It was difficult to predict my supervisor's attitude because today she's happy, tomorrow she's something else, hence I had to read her mood first before I knew what to do or say."

One can learn from the findings that it is difficult to work with a supervisor who is moody because the student must start by reading the mood of the supervisor first before saying or doing anything. This suggests that the progress of the study may be determined by the temperament of the supervisor. In contrast to this, literature reveals that personal problems should not interfere with student's work. Also, the literature warns that supervisors should guard against their behaviour (Chen et al., 2011) in relation to their students. Supervisors should note that it is difficult to work with a temperamental supervisor because he/she can throw tantrums anytime. When the supervisor is not in a good mood, he/she may not handle students professionally and well.

\section{Conclusion}

This research study was undertaken to explore ways that can erode supervisor-teacher trust. Following the findings of the analysed data, the study concludes that supervisors' behaviour towards their students can either enhance or erode trust. Supervisors who do not respect students, are intolerant, impatient or moody make it difficult for students to seek guidance and support in order to complete their studies. Long turnaround time retards the students' progress, and failure to understand their circumstances demoralises them.

As a sequel to these findings, this study recommends that supervisors should always recognise that the manner in which they interact with students may either make or break the trust between them. This study also recommends that supervisors should give feedback to students promptly, while students still remember what they wrote. Supervisors should always bear in mind that students have other big responsibilities, and take that into account when relating with them.

\section{Acknowledgements}

I would like to extend my gratitude to Professor MC Maphalala, former dean of University of Zululand, whose presentation about supervisor-student trust during workshop instigated the undertaking of this paper. I would also like to thank my wife Hlengiwe Dube for her overwhelming support during the course of this paper.

\section{References}

Barbour, R. S. (2014). Quality of data analysis. The SAGE handbook of qualitative data analysis, 496-510.

Bui, H.T. (2014). Student-supervisor expectations in the doctoral supervision process for business and management students. Business and Management Education in HE, 1(1), $12-27$.

Chen, X.P., Eberly, M.B., Chiang, T.J., Farh, J.L., \& Cheng, B.S. (2014). Affective trust in Chinese leaders: Linking paternalistic leadership to employee performance. Journal of Management, 40(3), 796-819. doi:10.1177/0149206311410604

Denis, C., Colet, N.R., \& Lison, C. (2019). Doctoral supervision in North America: Perception and challenges of supervisor and supervisee. Higher Education Studies, 9(1), 30-39.

Eller, L.S., Lev, E.L., \& Feurer, A. (2014). Key components of mentoring relationship: A qualitative study. Nurse Education Today, 34(5), 815-820. doi: 10.1016/j.nedt.2013.07.020

Falcone, R., \& Castelfranchi, C. (2009). Socio-cognitive model of trust. In C.S. Ang, \& P. Zaphiris (eds.), Human computer interaction: concepts, methodologies, tools, and applications (pp. 2316-2323). Hershey, PA: IGI Global. doi: 10.4018/978-1-60566-052 
Hauer, K.E., ten Cate, O., Boscardin, C., Irby, D.M., Iobst, W., \& O’Sullivan, P.S. (2014). Understanding trust as an essential element of trainee supervision and learning in the workplace. Advances in Health Sciences Education, 19(3), 435-456. https://doi.org/10.1007/s10459-013-9474-4

Holloway, I., \& Walker, J. (200o). Getting a PhD in health and social care. Oxford, Blackwell Science.

House, J.S. (1981). Work stress and social support. Reading, MA, Addison-Wesley.

Li, A.N., \& Tan, H.H. (2013). What happens when you trust your supervisor? Mediators of individual performance in trust relationships. Journal of Organizational Behavior, 34(3), 407-425.

Liñán, F., \& Fayolle, A. (2015). A systematic literature review on entrepreneurial intentions:

citation, thematic analyses, and research agenda. International Entrepreneurship and

Management Journal, 11(4), 907-933.

Lundh, P., Palmgren, P.J., \& Stenfors, T. (2019). Perceptions about trust: A phenomenographic study of clinical supervisors in occupational therapy. BMC Medical Education, 19(1), 1-9.

Lynn, A.B. (2005). The Eq Difference: A powerful program for putting emotional intelligence to work. New York: AMACOM.

Määttä, K. (2015). A good supervisor - ten facts of caring supervision. International Education Studies, 8(9), 185193. http://dx.doi.org/10.5539/ies.v8n9p18

McKnight, D.H., Cumings, L.L, \& Chervany, N.L. (1998). Initial trust formation in new organisational relationships. Academy of Management Journal, 59(3), 473-490.

Moxham, L., Dwyer, T., \& Reid-Searl, K. (2013). Articulating expectations for PhD candidature upon commencement: Ensuring supervisor/student 'best fit'. Journal of Higher Education Policy and Management, 35(4), 345-354. doi: 10.1080/136008oX.2013.812030

Nienaber, A.M., Romeike, P.D., Searle, R., \& Schewe, G. (2015). A qualitative meta-analysis of trust in supervisorsubordinate relationships. Journal of Managerial Psychology. 3o(5), 507-534. doi:10.1108/JMP-06-2013-0187

Thompson, D.R., Kirkman, S., Watson, R., \& Stewart, S. (2005). Improving research supervision in nursing. Nurse Education Today, 25(4), 283-290.

Venanzi, M., Piunti, M., Falcone, R., \& Castelfranchi, C. (2011). Facing openness with socio- cognitive trust and categories. Proceedings of the Twenty-Second International Joint Conference on Artificial Intelligence, Barcelona, Catalonia, Spain, July 16-22, 2011, 400-405. doi:10.5591/978-1-57735-516-8/IJCAI11-075.

Yin, R. K. (2012). Case study methods. In H. Cooper, P. M. Camic, D. L. Long, A. T. Panter, D. Rindskopf, \& K. J. Sher (Eds.), APA handbooks in psychology ${ }^{\circledast}$. APA handbook of research methods in psychology, Vol. 2. Research designs: Quantitative, qualitative, neuropsychological, and biological (p. 141-155). American Psychological Association. https://doi.org/10.1037/13620-009

Zheng, Y., Yu, S., Wang, B., \& Zhang, Y. (2019). Exploring student engagement with supervisor feedback on master's thesis: Insights from a case study. Innovations in Education and Teaching International, 57(2), 186197. https://doi.org/10.1080/14703297.2019.1617181 